\title{
Intoxication Anosognosia: The Spellbinding Effect of Psychiatric Drugs
}

\author{
Peter R. Breggin, MD \\ Ithaca, NY
}

\begin{abstract}
Why do so many individuals persist in taking psychoactive substances, including psychiatric drugs, after adverse mental and behavioral effects have become severe and even disabling? The author has previously proposed the brain-disabling principle of psychiatric treatment that all somatic psychiatric treatments impair the function of the brain and mind. Intoxication anosognosia (medication spellbinding) is an expression of this druginduced mental disability. Intoxication anosognosia causes the victim to underestimate the degree of drug-induced mental impairment, to deny the harmful role that the drug plays in the person's altered state, and in many cases compel the individual to mistakenly believe that he or she is functioning better. In the extreme, the individual displays outof-character compulsively destructive behaviors, including violence toward self and others.
\end{abstract}

Keywords: adverse drug effects; psychiatric medications; drug-induced cognitive deficits; toxicology; substance abuse

nosognosia is defined as unawareness or denial of a neurological deficit or, more
broadly, ignorance of the presence of disease. The concept originated in the ob-
servation that individuals with nondominant parietal lobe lesions (e.g., stroke) sometimes fail to recognize an associated paralysis on the other side of the body. In an enlightening essay, Fisher (1989) enlarged the concept of anosognosia and described it, along with memory dysfunction, as one of the constant features of brain damage and dysfunction.

Defining anosognosia as "the capacity of brain damage to cause denial of lost function," I have previously used the concept to explain aspects of the brain-disabling principle of psychiatric drugs-that all physical treatments in psychiatry work by causing brain dysfunction and disability (Breggin, 1997, p. 10). In this article I want to examine a specific brain-disabling effect that I have labeled medication spellbinding or intoxication anosognosia.

\section{THE IMPORTANCE OF MEDICATION SPELLBINDING}

A huge percentage of the population uses legal recreational drugs such as caffeine, nicotine, and alcohol despite considerable public health efforts to warn about their harmful effects. Another large percentage uses illegal drugs such as marijuana, methamphetamine, 
cocaine, and heroin despite concerted efforts to alert the public about their dangers. Finally, another significant percentage of the population uses psychiatric drugs-including stimulants and antidepressants--whose safety and efficacy have become increasingly controversial and subject to Food and Drug Administration (FDA) review.

Why do so many people take psychoactive medications, even in the face of obviously harmful effects and often despite questionable benefits? There are of course many potential explanations why human beings have such a strong tendency to use drugs that impair the function of their brains and minds. Here I want to focus on one specific biological mechanism that encourages and even at times seems to compel drug taking.

If all psychoactive drugs possess qualities that tend to encourage, facilitate, or compel usage, then it may help to explain the widespread use of psychiatric drugs as well as recreational drugs. In the past, most warnings about the beguiling or seductive effects of drugs have focused on recreational and illegal substances--but can the same or similar effects be found in the action of all psychoactive agents, including prescribed psychiatric medications?

Some psychiatric drugs, such as the stimulants and benzodiazepines, cause changes in the brain that lead to dependency and withdrawal problems. There is increasing evidence that most or all psychiatric drugs cause sufficient withdrawal problems to interfere with efforts to stop taking them (Breggin, 1997; Breggin \& Cohen, 1999). Dependence and withdrawal problems in themselves, however, do not fully account for the widespread use of a broad array of psychoactive agents, including nonaddictive psychiatric drugs, such as the antidepressants, lithium, and neuroleptics.

\section{REVIEWING NUMEROUS CASES}

I have reviewed several dozen cases, selected from many years of clinical and forensic practice in which I have evaluated individuals who developed suicidal, violent, or criminal impulses or behaviors while under the influence of psychiatric drugs. The most common medication offenders have been the newer antidepressants, benzodiazepines (antianxiety sedatives), and stimulants, but all categories of psychiatric drugs have been involved, including mood stabilizers and neuroleptics.

One of the most frequent and serious offenders has been the combination of selective serotonin reuptake inhibitor (SSRI) antidepressants and benzodiazepines, especially alprazolam (Xanax). In one case, a man with no prior criminal history began taking fluoxetine (Prozac) and alprazolam to reduce the strain before starting a new and exciting job. He began to watch videos of the movie The Saint and decided it would be fun to mimic him. He robbed his wife's bank, his mother's bank, and his local drugstore wearing a minimal disguise. Before one of the robberies, he stood outside discussing his vintage automobile with a passerby. He was easily apprehended and seemed to have no idea what the fuss was about until the medications wore off. He was mostly worried about making an upcoming business appointment. He thought he was doing fine-or better than ever.

During the robberies, this man was suffering from a substance-induced mood disorder with manic features. He had no history of any violent or criminal activity and denied any fantasies about committing crimes before being placed on the medications. In my report in his criminal case, I emphasized that he suffered from an organic, drug-induced neurological disorder (substance-induced mood disorder with manic features) and not from an 
ill-defined mental disorder. Due to my report and a corroborating report from an expert hired by the state, he was found not guilty by reason of insanity caused by psychiatric drug intoxication.

In another case involving the same two drugs, fluoxetine and alprazolam, administered over a longer period of time in higher doses, a businessman became dependent on the alprazolam and also developed manic-like symptoms. After he was charged with insider trading, he was unable to adequately defend himself and was in my opinion wrongly convicted. While incarcerated he underwent a severe withdrawal from alprazolam. He too had failed to perceive what was happening to him until he was removed from the drugs. In fact, he thought he was performing on an especially high level.

Another man became psychotic shortly after starting to take sertraline (Zoloft) and believed that his wife had been taken over by a dangerous alien from another world. In order to destroy the alien inside her, he drove their car into a barrier. She was thrown from the car, and he tried to beat her to death as she lay helpless be the roadside. Fortunately, she survived. In a case in which I played no role, he was found not guilty by reason of insanity. Only after he began to recover, over the subsequent weeks of psychiatric incarceration, did he begin to suspect that medications might have caused his psychosis. He was released after several months of commitment to a mental hospital and allowed to remain in the community under supervision. His therapist recommended that I take over the psychiatric portion of his treatment. I gradually removed him from a cocktail of medications and he has done very well during a several-year follow-up. He suffered from a substance-induced mood disorder with mixed manic and depressive features, and psychosis. He did not experience a manic euphoria but he did believe he was on a mission to save himself and the world.

The above cases all had manic features. In other cases, compulsive suicidal or violent behaviors developed without associated manic-like features. A 16-year-old girl was begun on fluoxetine (Prozac) to relieve the stress she was undergoing while being diagnosed for an obscure gastrointestinal disorder that eventually went away. Shortly after starting on the fluoxetine, she felt compelled to stab her mother to death but experienced no other adverse drug effects. At the last moment, she confessed her intentions to her mother, and she recovered completely when removed from the antidepressant. She was, however, left with years of wrestling with how she could have done such a thing. Now in her 30s, she felt relief after talking with me about what had happened to her and how frequently other good people have developed bizarre impulses on these medications. She had no prior history of suicidality or violence, and she has not experienced any since coming off the medication years ago. There were no legal ramifications to the case.

In another case, a man who had recently been begun on paroxetine (Paxil) for mild chronic depressed feelings became obsessed with killing himself. He drove his car into an unsuspecting policeman in order to knock him down and obtain his gun. Fortunately, he did not kill the officer, and a bystander prevented him from obtaining the gun. He was agitated but not manic during the episode. After my report in his case, the police officer agreed that drugs must have driven his impulsive action, and an agreement was reached that led to only a brief incarceration. On follow-up, he has done well for several years. Although there are numerous references in the literature to compulsive suicidality, there are fewer that describe compulsive violence.

In all cases the suicidal, violent, or criminal behaviors were unprecedented in the individuals' lives and seemed in retrospect to be very alien and inexplicable to them. None of 
the acts were repeated after the individual stopped taking the medications. In evaluating the cases, I interviewed surviving victims of drug toxicity and their families and acquaintances. In all of several dozen cases, except for the 16-year-old with the compulsion to stab her mother, I had complete access to detailed medical, school, and occupational records. In many of the cases, my reports led to acquittal on the basis of involuntary intoxication, reduced charges, shortened sentences, or release from incarceration. Most of the cases were evaluated for legal purposes, but a number were clinical consultations.

As the patterns have emerged from reexamining these cases, I have been struck by the fact that victims of drug-induced abnormal mental states and behavior almost never seem to have an inkling that they are acting irrationally or that they are under the influence of their psychiatric drugs.

As another example of the failure to perceive mental dysfunction or drug-induced toxicity, a young man committed a series of eight knife-point robberies of his local gas stations, including those he and his family frequented. He used no disguise and was even warned on one occasion that a surveillance camera was photographing him. He was of course easily caught. He had been recently started on paroxetine (Paxil), which was continued during his trial and sentencing. He was allowed to return home briefly before beginning a lengthy incarceration and immediately robbed another local gas station using an identical knife and the same automobile, and he was easily apprehended.

Only after the medication was stopped did he return to his premedication mental state and grasp how irrational and disastrous his behavior had been. At no time while taking the drugs did he, or any of my other cases, realize that he was acting bizarrely and might be under the influence of medication. My report in the case led to a greatly reduced sentence.

Familiarity with medication effects does not necessarily prevent spellbinding. In several cases, the victims of drug intoxication were physicians, including one sophisticated psychiatrist who assaulted a female colleague and made a bizarre suicide attempt while taking fluvoxamine (Luvox). He was convicted of assault and continued on the antidepressant in prison. He did not realize that the drug might have been involved in his behavior until he was removed from it several months later. By the time he asked me to consult with him while he was in jail, it was too late to change the outcome, and his sentence would soon be over. However, he was vastly relieved to learn from me that many others had also become unaccountably violent while taking the newer antidepressants.

These adverse drug reactions are extreme, of course, and not typical of most people exposed to these agents. But I believe they provide a window into the drug-induced phenomena that affect most if not all individuals who receive sufficient medication to modify their mental condition.

\section{SPELLBINDING OR INTOXICATION ANOSOGNOSIA}

Three related themes run through all of these cases. First, the individuals fail to perceive that they are acting in an irrational, uncharacteristic, and dangerous manner. Second, they fail to identity the medication as playing any role in their drastically changed mental processes and activities. Third, they often think that the medication is helping, although sometimes they believe it is ineffective, and they continue to take it as they deteriorate mentally. Fourth, in the extreme these individuals become compulsively driven to per- 
petrate out-of-character violence against themselves or others, often in a drug-induced manic-like state appropriately diagnosed as a substance-induced mood disorder with manic features (Breggin, 2003).

These observations led me to examine what I initially identified as the "spellbinding effect" of psychoactive drugs-more technically, intoxication anosognosia-the failure to recognize the harmful mental effects of psychoactive agents and the accompanying tendency to overestimate their positive mental effects. This spellbinding effect is probably the most important reason why psychoactive drugs are so widely used. People under the influence of psychoactive agents fail to appreciate their harmful effects and overestimate their positive ones.

The spellbinding effect of psychoactive drugs leads intoxicated people to become deeply mired in trouble before grasping what they are doing to themselves and to others. The same spellbinding effect causes many psychiatric patients to accept prescribed medications without realizing how much they are being harmed and how little they are being helped.

\section{RELATIONSHIP TO THE BRAIN-DISABLING PRINCIPLE}

The spellbinding effect is a corollary to a series of observations that I have previously named the brain-disabling principle of psychiatric treatment (Breggin, 1997). The braindisabling principle states that all psychiatric treatments cause brain dysfunction, that brain disability is the primary "therapeutic" effect, and that cases are seen as successful when this impairment is interpreted as an improvement. The principle applies to lobotomy, electroshock, and all psychiatric medications.

In summary form, here are the first 4 of 11 brain-disabling principles (modified from Breggin, 1997):

1. All biopsychiatric treatments share a common mode of action-the disruption of normal brain function. None of them improve brain function.

2. All effective biopsychiatric interventions work by causing generalized brain dysfunction, affecting both emotional and cognitive functions. In a somewhat dose-dependent fashion, all biopsychiatric interventions impair overall mental function.

3. Biopsychiatric treatments produce their "therapeutic" effect by impairing higher human functions, including emotional responsiveness, social sensitivity, self-awareness or selfinsight, autonomy, and self-determination. More drastic effects include apathy, euphoria, and lobotomy-like indifference. When the disruption in normal function is interpreted as advantageous, the treatment is considered successful. A positive interpretation is often made by the physician or family but not by the patient. Sometimes patients also prefer the impaired state because it dulls their self-awareness and suffering or causes an artificial euphoria, or because of placebo effects.

4. Each biopsychiatric treatment produces its essential or primary brain-disabling effect on all people, including normal volunteers and patients with varying psychiatric diagnoses. The effect is not specific for any psychiatric disorder. To the extent that it can be measured, the effect will occur in normal mammals. Antipsychotic drugs, for example, impair basal ganglia and frontal lobe function in all people and mammals, causing disinterest and subdued behavior, making individuals apathetic toward themselves and docile (Breggin, 1997). Stimulant drugs also impair basal ganglia function and frontal lobe function, sup- 
pressing spontaneity and producing obsessive-compulsive behavior in all people and mammals, making children less social, more compliant with obsessive tasks, and more docile (Breggin, 1999a, 1999b). Benzodiazepines enhance gamma-aminobutyric acid (GABA) function, causing a generalized suppression of central nervous system (CNS) function and ultimately sleep and anesthesia in all people and mammals, sometimes blunting anxiety in the process (Breggin, 1998a). The SSRI antidepressants disrupt serotonin neurotransmission throughout the brain, causing mental effects that are not easily measured in animals. In humans, they cause a range of impairments from blunting of affect to a stimulant syndrome with euphoria and mania, all of which are sometimes interpreted as improvement by others or experienced as relief by the patient. (Breggin, 2003)

The spellbinding effect defines a specific nuance of the brain-disabling principle-the tendency of individuals to respond to brain-disabling effects by failing to perceive their existence or severity, by failing to link them to the drug, by overestimating the supposed benefits, and sometimes by perpetrating compulsively destructive acts.

Any psychoactive agent can cause mental dysfunction and lead to spellbinding. Less obviously, many medications used for nonpsychiatric purposes-including cardiovascular drugs, antihypertensive agents, steroids, and even some antibiotics--have a marked potential to cause mental dysfunction. Farlow and Hake (1998) review numerous classes of medication that can cause cognitive dysfunction. When a psychoactive agent interferes with brain function, it can produce toxicity anosognosia (spellbinding). The individual who becomes agitated on an antibiotic, for example, exactly like an individual who becomes agitated on an antidepressant, is not likely to perceive the severity of the mental changes, is not likely to associate the changes with the medication, and, if severely affected, may think he (or she) is doing better than ever. Again, like the person agitated by an antidepressant, the individual may blame the agitation on a friend, loved one, or stranger, with potentially harmful results.

\section{ALCOHOL: THE PARADIGM}

Alcohol intoxication provides a paradigm for spellbinding or intoxication anosognosia. Individuals who are mildly intoxicated on a few ounces of alcohol will often underestimate their impairment and overestimate the positive effects. As a typical example, an individual who thinks he is the life of the party may turn out to be the death of it. More tragically, the individual who feels able to drive his automobile may in reality pose a threat to himself and others.

The spellbinding effect of alcohol has probably been recognized since before recorded history. Nonetheless, individuals in each new generation too often have to learn for themselves. Young people are notoriously vulnerable to drinking too much alcohol, resulting in humiliating or dangerous behavior, including many fatal car crashes. Only after a few bad experiences do many youngsters learn to set limits on their drinking and to recognize warning signs of intoxication.

Compared to people who become intoxicated on psychiatric drugs, individuals who are drunk are more likely to perceive that they are under the influence of their drug. They may underestimate the degree of toxicity but they are likely to know they are being affected. Of course, this is not always the case, and quite often people have to be reminded 
by friends or family that they are showing the effects of drinking too much. Often the intoxicated individuals will deny the effects and become resentful.

Nonetheless, in comparison to psychiatric drug users, alcohol users are more likely to realize that their drug is influencing their behavior. There are several reasons for this. First, the half-life of alcohol is very short and individuals often begin to recover ("sober up") from acute intoxication within an hour or two of peaking. Therefore, it may seem as if they knew they were "under the influence," but for a time they were unaware of their degree of intoxication.

Second, all adults and many children are well aware of alcohol's intoxicating effects and easily recognize the significance of slurred speech or a stumbling gait, at least in other people. By contrast, the vast majority of people who take prescribed psychiatric medications have no prior experience with the intoxicating effects of these drugs. Neither they nor their friends are likely to know the warning signs of incipient intoxication from a prescribed medication. People in general are largely unaware that psychiatric drug intoxication frequently involves predominantly psychiatric (mental) adverse effects. Such effects are seen in the stimulant profile of SSRI antidepressant adverse effects, which includes insomnia, nervousness, anxiety, akathisia (psychomotor restlessness), irritability, hostility and aggression, emotional instability, and mania. Indeed, too many professionals seem to lack awareness of psychiatric adverse drug effects, leading to the recent FDA label revisions for antidepressants, which list each of those stimulant effects (Food and Drug Administration, 1995).

Third, people in contact with a person who is drunk are likely to remind him that he has had too much to drink; but people in contact with a person intoxicated on a psychiatric drug are not likely to identify symptoms like agitation, irritability, and mood instability as potential adverse drug effects. Very likely, they will not even know that the person has recently taken a psychiatric drug.

Fourth, most psychiatric drug intoxications do not cause gross physical manifestations, such as slurring of speech or stumbling. The benzodiazepines can cause these gross symptoms, but the benzodiazepines can cause serious mental disability without the individual looking drunk (Breggin, 1998a).

\section{SOCIAL REINFORCEMENT FOR SPELLBINDING}

Although the primary spellbinding effect is due to intoxication and brain dysfunction, spellbinding is reinforced by social factors, making psychiatric drugs perhaps the most spellbinding of all psychoactive agents. Individuals who take psychiatric drugs expect them to be helpful. While they know the drugs may prove ineffective, they do not suspect that they frequently cause adverse drug reactions that impair mental and emotional function. Nearly everyone believes that the FDA would not approve a psychiatric drug that frequently worsened psychiatric symptoms, when in fact a quick glance at any FDA-approved psychiatric drug label will confirm that every psychiatric medication causes a variety of negative mental effects, some of them very serious, including anxiety, depression, mania, and aggression.

When people start feeling worse after a starting a psychiatric drug, they usually attribute it to their declining mental condition. When the drug fails to work, they may become despairing in their belief that "nothing can help me," when in fact the drug is making 
them worse. In addition, the individual is likely to have been exposed to the deluge of promotional materials in favor of medications that is put out by the drug companies, medical and psychiatric authorities, and government agencies. All of this reinforces one aspect of spellbinding - the individual's failure to recognize that the drug is causing his mental deterioration.

Often doctors reinforce spellbinding by dismissing a patient's concerns about agitation, anxiety, or worsening depression after starting a psychiatric drug. Physicians rarely give adequate warnings to their patients concerning the adverse psychiatric effects of drugs. Physicians almost never attribute a patient's decline to his psychiatric drugs. In none of my many cases did the prescribing physician realize that his patient was deteriorating as a result of the treatment. In many cases, the doctor rejected warning phone calls from family members, and in many cases the doctor raised the dose of the drug despite the emergence of adverse drug reactions of a psychiatric nature. Despite the new label changes for antidepressants, there was need for me to publish a recent article alerting primary care physicians and practicing psychiatrists to the dangers posed by these agents (Breggin, 2006b).

\section{ACUTE INTOXICATION}

From my clinical experience and research (Breggin, 2003) and from my analysis of sealed drug company files (Breggin, 2006a), it has become apparent that drug-induced psychiatric adverse reactions are most likely to occur when a drug has been started, when the dose has been changed, or when the drug is stopped. Recently the FDA has incorporated these observations into its new requirements for psychiatric drug labels, with specific warnings that adverse psychiatric effects are more frequent when medications are started or stopped, or doses are adjusted (Food and Drug Administration, 2005).

\section{CHRONIC SPELLBINDING}

Users of intoxicants can become chronically spellbound. That is, they can use drugs for months or even years at a time without grasping that they are mentally impaired, that the drugs are causing the impairment, that they are not truly benefiting from the drugs, and in extreme cases that they have become compulsively destructive to themselves and to others. All this is familiar to anyone who has dealt with chronic alcoholics. However, in my experience, spellbinding is an inevitable outcome of the chronic use of any psychoactive agent.

In psychiatry, this spelibinding effect is commonly recognized in individuals who are prescribed benzodiazepines over the long term. Often the individual becomes dependent and impaired without realizing it. Antidepressants also have long-term negative effects that patients fail to detect. Time and again I have evaluated patients who have been taking antidepressants for years without realizing that their emotions have become numb, that the drug is causing the numbness, and they are not functioning as well as they might in a whole range of activities. 


\section{VARYING EFFECTS OF MEDICATIONS}

Medication spellbinding or intoxication anosognosia will vary in some of its qualities depending on the drug. The antidepressants, as already noted, commonly produce a continuum of stimulation that the person does not recognize as a drug effect. In the extreme, it becomes drug-induced mania (Breggin, 2003, 2006b), a condition in which the individual is ecstatically spellbound into believing that he or she is functioning at a fantastic level. The antidepressants can also produce a dulling or stupefying effect, especially with chronic use. Again, the individual will not recognize the severity of the condition or its relationship to the drug, and may feel he is functioning better. The benzodiazepines produce an array of spellbinding effects that are very similar to the effects of alcohol but often without the telltale drunkenness with slurred speech and stumbling that alerts the individual to intoxication. The stimulants produce a continuum of stimulation similar to that produced by the antidepressants, but they also produce a specific phenomenon of reduced spontaneity. The more apathetic, and hence more docile, medicated child may be perceived as improved by parents and teachers, and even by himself in his desire to stay out of trouble. The neuroleptics produce devastating frontal lobe dysfunction by blocking dopamine neurotransmission, producing a virtual chemical lobotomy (Breggin, 1997). In many ways the epitome of spellbound, they can become zombie-like. In the extreme, patients intoxicated with neuroleptics become wholly under the thrall of the drug, robotic, and unable to think and act for themselves.

\section{ASSOCIATED EFFECTS OF SPELLBINDING: AMNESIA}

When drug intoxications become more intensive and disabling, two additional phenomena complicate the result: memory loss and depersonalization for the period of intoxication.

In every one of the several dozen extreme cases I have reviewed, there was some degree of memory loss with regard to the events. Sometimes it was spotty and sometimes it was complete. The memory failure usually did not mature until several hours after the intoxication and the associated traumatic events, so that the individual was often able to recount the recent events to the first emergency responders or police on the scene. Later in the day, however, the individual usually began to discover that the memories were gone. Drug intoxication interferes with the laying down of permanent memories rather than with immediate recall. If, however, the individual was delirious or otherwise grossly mentally impaired during the intoxication, he or she may never experience a brief interval of normal memory function.

Many of the patients in my series were deeply distressed at their amnesia with regard to the critical events, and they worked hard to try to recall as much as they could. In an effort to reconstruct what happened, they examined records and talked to people who knew what had happened. I usually interviewed them weeks or months after the intoxication, and by then they could no longer easily distinguish between what they recalled and what they had learned retrospectively from other sources. The experience was confusing and they always felt it hampered their defense in criminal cases.

Were some of these people feigning memory loss in order to seem less responsible for their actions? It is always possible, of course, that people will concoct falsehoods to further 
their defense in criminal cases or to bolster their suits against doctors or drug companies. However, most of these patients made enormous efforts to reconstruct events, indicating a strong desire to reconstruct what had happened. Also, none of these people had a prior criminal history. None of them had been diagnosed as sociopathic. Their families and associates viewed all of them as honest people. None of them were previously known as liars or manipulators. Many provided me with information that in fact hindered their cases. And in a few examples, patients had no legal ax to grind and yet the same amnestic pattern persisted.

With regard to the consistently high quality of the character of the several dozen people in this series, they were selected on that basis. I vet my legal cases before taking them and if I discover at some point that I cannot trust the individual, I remove myself from the case. ${ }^{1}$

\section{ASSOCIATED EFFECTS OF SPELLBINDING: DEPERSONALIZATION}

Depersonalization and derealization were manifested in many but by no means all of the cases. An individual would report that he had watched his hand fire the gun as if it were someone else's hand. Commonly people reported that the experience was like a dream or trance. Of course, all of these are common phenomena in association with any trauma. I saw no unusual or atypical characteristics to these experiences and could not find a way to specifically identify them as drug induced.

\section{SPELLBINDING AND CREATIVITY}

The spellbinding effect is part of a broader dysfunction that impairs the frontal lobes and limbic system, including creativity, self-awareness, social sensitivity, emotional control, judgment, and planning. In effect, any degree of psychoactive drug toxicity is likely to diminish all the characteristically human qualities that we value. Individuals may think that they are more creative, more insightful, or more loving than ever while under the influence of psychoactive agents, but the ultimate result is usually stereotyped and limited. Since psychiatric drugs do not usually cause the perceptual distortions associated with psychedelics, taking psychiatric drugs rarely even produces an illusion of creativity.

\section{A BIOLOGICAL OR PSYCHOLOGICAL EFFECT?}

Is there a difference between spellbinding (intoxication anosognosia) and psychological denial - the refusal to take responsibility for facing reality, especially the consequences of one's actions? Am I committing an offense that I have frequently criticized in othersscientism or the mistaken application of simple-minded biological principles to complex psychological, social, and spiritual phenomena? Perhaps worse, am I giving people an excuse for bad behavior? My own reluctance to make these intellectual and ethical errors has, if anything, delayed my drawing these conclusions in their most complete form.

Psychiatric drugs do not spellbind everyone. Many people do sense when a psychiatric drug is impairing them, and they stop taking it before they run into serious trouble. This is true of most drugs, including legal and illegal recreational drugs, even those that cause 
dependency. Some individuals sense that a problem is developing and stop taking the drug, at least in excess. But the fact that some people are more able than others to resist a drug effect does not resolve the question of the effect's biological or psychological origin. Variation in response can be physical or emotional in origin.

Most probably, a variety of factors play a role in the intensity or direction of a drug's effect, including the qualities of the drug and its dose, the biological sensitivity and physical health of the individual, the psychological makeup of the individual, the individual's knowledge of drug effects, the setting in which the individual lives, and the individual's support system.

Similarly, psychoactive drugs do not spellbind everyone, but they do have beguiling characteristics that ensnare many unfortunates. Who gets ensnared may depend on many factors, but the purpose of this analysis is to establish that there is in fact a phenomenon I am calling medication spellbinding or intoxication anosognosia. My clinical experience suggests that most people who continue taking psychiatric drugs for lengthy periods of time suffer from spellbinding or intoxication anosognosia.

The strongest argument for the biological nature of spellbinding is its consistency as a finding across the spectrum of brain dysfunction, from psychoactive substance intoxication to traumatic brain injury and dementia from any cause. After lobotomy, patients often deny that anything at all has happened to them. I have evaluated cases in which patients undergoing shock treatment dutifully submitted to ever-increasing brain damage until family members intervened and halted the treatment (Breggin, 1998b).

This general clinical phenomenon of anosognosia is found in virtually every form of brain dysfunction. It can even be seen in individuals who are tired or exhausted due to lack of sleep, overexertion, or illness. Commonly they do not grasp the degree of their impairment and fail to perceive any connections between how they are feeling and their lack of sleep, overexertion, or illness. In some instances, these individuals develop a false sense of well-being and ability. Concerned others have to remind them that they are overdoing it, that they have lost "their edge" and need to rest.

Any trauma to the brain and to mental function can have a spellbinding impact on the individual. Acute accident victims with head trauma often fail to appreciate that they are severely injured and will attempt to refuse medical attention, even though they cannot function. A friend of mine fell headlong into a wall while running on a slippery pavement. He broke his finger, cut his face severely, and suffered a concussion. As he staggered to his feet, he explained that he was fine. Although we were on our way to lunch, he decided he was actually on a shopping trip to the store whose outer wall he had collided with. With blood dripping down his face, he tried to stumble into the store and had to be led back to the car and taken to an emergency room. Was he responsible for behaving so foolishly? I do not believe so. A blow on the head spellbound him.

I have already discussed the familiar phenomena of alcohol intoxication, which routinely beguiles the individual into underestimating the drug-induced impairment, into failing to appreciate that the drug is driving his atypical behavior, and into falsely believing that he is functioning better than ever. It is not by chance that alcohol is so frequently involved in crimes of violence and other expressions of disinhibition.

Marijuana intoxication provides another familiar and often comical example of spell. binding. Individuals smoking "dope" often behave like dopes. In particular, they commonly think they are sharing incredibly funny and insightful banter. But to the drug-free observer, there is little humor and no insight at all. 
The frequency with which spellbinding is associated with short-term memory loss is another argument for its biological source. In discussing the amnestic syndrome that follows trauma to the brain, Bourgeois, Seaman, and Servis (2003, p. 294) confirm that "Most patients with amnestic disorders lack insight into their deficits and may vehemently deny the presence of memory impairment despite clear evidence to the contrary. This lack of insight may lead to anger, accusations, and occasionally agitation." These authors also point out that confabulation is frequently associated with amnestic syndromes. In answer to questions that require memory, the confabulating individual gives false and often wildly implausible answers. The authors believe that confabulation is more than a psychological defense aimed at covering up the deficits and that it may relate to "loss of self-corrective and monitoring functions, as seen in bifrontal lobe disease." Again, as in my experience with patients after intoxication, confabulation occurs in the early stages after the trauma and tends to disappear over time.

In discussing the brain-disabling principle of psychiatric drugs (Breggin, 1997), I applied the concept of anosognosia to the well-documented finding that many patients with tardive dyskinesia deny that they suffer from abnormal movements (also see Myslobodsky, 1986). Tardive dyskinesia is a common and usually irreversible movement disorder caused by neuroleptic medications. Many individuals with tardive dyskinesia can identify obvious muscle twitches and spasms in other patients but not in themselves. The effect is mostly observed in psychiatric hospital inmates and may be due to a combination of chronic brain damage and acute intoxication caused by neuroleptic drugs.

In lobotomy, the individual becomes robotically spellbound. Self-insight is so obliterated that previously fluent individuals cannot write a few simple sentences about themselves. Typically they fail to recognize that they are enormously impaired. Robbed of their capacity for motivation or self-determination, they do not perpetrate bizarre crimes but are easily led by others. A similar robotic reaction is seen in patients or inmates who are prescribed neuroleptics and in children who are prescribed stimulants. Again due to frontal lobe disruption, they become more docile and manageable. Often (but not always) they fail to perceive their degree of impairment and do not know that the medications have made them behave in uncharacteristic ways.

Traumatic injury to the frontal lobes, lobotomy, neuroleptic medications, and stimulant medications affect animals in the same manner as they affect humans. Of course, we cannot know the nonverbal animal's mind, so it is difficult to evaluate his degree of anosognosia. But the animal's outward behavior is identical to that of humans. The braininjured, lobotomized, or drugged animal loses his self-determination, his behaviors become more narrow and compulsive, and he becomes more docile and robotic.

Controlled clinical trials involving psychiatric drugs provide another strong argument to support the biological origin of spellbinding. In every clinical trial I have ever evaluated, subjects taking a psychiatric drug have more adverse psychiatric effects than subjects taking a placebo. Mania is a particularly common serious adverse psychiatric reaction to antidepressant medications. It is an established fact that more people will become manic while taking antidepressants than while taking plecebos. Drug-induced mania is the prototype and extreme example of spellbinding.

While anosognosia in one form or another is seen in many varieties of brain dysfunction, the overall phenomenon of spellbinding seems particularly clear-cut in cases of drug intoxication, in which, often over a prolonged period of time, individuals fail to perceive 
their worsening condition, fail to perceive that the drug is causing disability, instead feel benefited or improved, and in some cases become compulsively destructive.

\section{THE ROLE OF PSYCHOLOGY AND ETHICS}

Are some people more psychologically prone to becoming spellbound by drugs? Common sense and clinical wisdom would suggest that psychological vulnerability plays a role in the impact of any stress, including drug intoxication. There is a wide spectrum of human biological and psychological responses to drugs, and we must assume that predisposition plays a role. Does that mean that violence-prone and suicide-prone people are more likely to become violent or suicidal when under the influence of a psychiatric drug? Again, common sense and clinical wisdom suggest that this is so. There are also confirmatory data. In clinical studies, individuals who have suffered a manic-like episode are more likely than others to become manic while taking an antidepressant. Nonetheless, many people with no known history of manic-like episodes will become floridly manic while taking antidepressants (Breggin, 1997).

In my clinical and forensic experience, many cases of drug-induced murder, mayhem, and suicide occur in individuals who were recognized as model citizens prior to their drug intoxication. Usually I do not take cases for legal review unless the past history of the individual concerned is negative for similar destructive behaviors. Many (but not all) of the victims of drug-induced abnormal behavior in my series were shy and perhaps cautious individuals. Were they psychologically inhibited people who broke loose under the influence of drugs and expressed their underlying frustrations or fantasies? I found no evidence for predispositions of this kind in my in-depth clinical evaluations, which usually included a review of all the medical, occupational, educational, and legal records and collateral interviews with family, friends, and work associates. As group they were law-abiding, ethical human beings, and it is purely speculative to impugn unconscious motivations toward violence or toward suicidal or criminal behavior.

Regardless of any scientific data, all people should be encouraged at all times to take full responsibility for themselves. That is the responsibility of human beings in every area of their lives whether they are healthy or ill, sober or intoxicated. In my clinical practice I often deal with people who have been brain injured by accidents, lobotomy, electroshock, recreational drugs, or psychiatric medications. I always remind them of the power of the human spirit to overcome and transcend physical disability, including brain damage and dysfunction.

While it is important in helping people to emphasize the central role of personal responsibility and self-determination in their lives, in evaluating their prior conduct we need to take into account their level of brain function. From lobotomy to drug intoxication, loss of brain function makes it hard and at times impossible for human beings to maintain a high level of ethical functioning. Psychoactive medication induces brain dysfunction that tends to spellbind the victim so that he or she has little awareness of being impaired and no awareness that the drug is causing problems. Often there is an element of euphoric overestimation of one's mental condition and conduct.

Most of the individual observations that I have made are drawn from my clinical experience and general medical knowledge, and some of my observations about anosognosia 
have been well researched. Hopefully my observations will ring true for other clinicians and researchers concerned with drug effects. Certainly many of my individual points are well known and broadly accepted. Prior to this time, however, the observations have not been brought together into a unitary concept of medication spellbinding or intoxication anosognosia.

In summary, medication spellbinding or intoxication anosognosia leads the victim to underestimate the degree of his (or her) drug-induced mental impairment. It also causes him to fail to recognize that the drug plays a role in his changed mental state or behavior. He may think that the drug is having no impact or that it is having some beneficial effect. In extreme cases, typified by drug-induced euphoria or mania, the individual believes that he is functioning better than ever, when the drug in fact is severely mentally impairing him, and driving him toward compulsively destructive actions.

Medication spellbinding or intoxication anosognosia probably affects most people who take psychoactive drugs, including most patients who are prescribed psychiatric drugs. It helps to explain why so many people take nonpsychiatric and psychiatric drugs despite the fact that they are doing more harm than good.

\section{NOTE}

1. Obviously, the standards for withdrawing from clinical or treatment cases would be much more complex.

\section{REFERENCES}

Bourgeois, J., Seaman, J., \& Servis, M. (2003). Delirium, dementia, and amnestic disorders. In R. Hales \& S. Yudofsky (Eds.), Textbook of clinical psychiatry (pp. 259-308). Washington, DC: American Psychiatric Publishing.

Breggin, P. (1997). Brain-disabling treatments in psychiatry. New York: Springer Publishing.

Breggin, P. (1998a). Analysis of adverse behavioral effects of benzodiazepines with a discussion of drawing scientific conclusions from the FDA's spontaneous reporting system. Journal of Mind and Behavior, 19, 21-50.

Breggin, P. (1998b). Electroshock: Scientific, ethical, and political issues. Intermational Journal of Risk and Safety in Medicine, 11, 5-40.

Breggin, P. (1999a). Psychostimulants in the treatment of children diagnosed with ADHD: Part I: Acute risks and psychological effects. Ethical Human Sciences and Services, 1, 13-33.

Breggin, P. (1999b). Psychostimulants in the treatment of children diagnosed with ADHD: Part II: Adverse effects on brain and behavior. Ethical Human Sciences and Services, 1, 213-242.

Breggin, P. (2003). Suicidality, violence and mania caused by selective serotonin reuptake inhibitors (SSRIs): A review and analysis. Ethical Human Sciences and Services, 5, 225-246.

Breggin, P. (2006a). Court filing makes public my previously suppressed analysis of Paxil's effects. Ethical Human Psychology and Psychiatry, 8, 77-84.

Breggin, P. (2006b). Recent regulatory changes in antidepressant labels: Implications for activation (stimulation) in clinical practice. Primary Psychiatry, 13, 57-60.

Breggin, P., \& Cohen, D. (1999). Your drug may be your problem. Cambridge, England: Perseus Books. 
Farlow, M., \& Hake, A. (1998). Drug-induced cognitive impairment. In J. Biller (Ed.), Iatrogenic neurology (pp. 203-214). Boston: Butterworth-Heinemann.

Fisher, C. M. (1989). Neurological fragments: Remarks on anosognosia, confabulation, memory, and other topics: An appendix on self-observation. Neurology, 39, 127-132.

Food and Drug Administration (FDA). (2005, January 26). Class suicidality labeling language for antidepressants. Food and Drug Administration, Rockville, MD. Retrieved September 2, 2006, from http://www.fda.gov/cder/drug/antidepressants/PI_.template.pdf

Myslobodsky, M. S. (1986). Anosognosia in tardive dyskinesia: "Tardive dysmentia" or "tardive dementia"? Schizophrenia Bulletin, 12, 1-6. 